
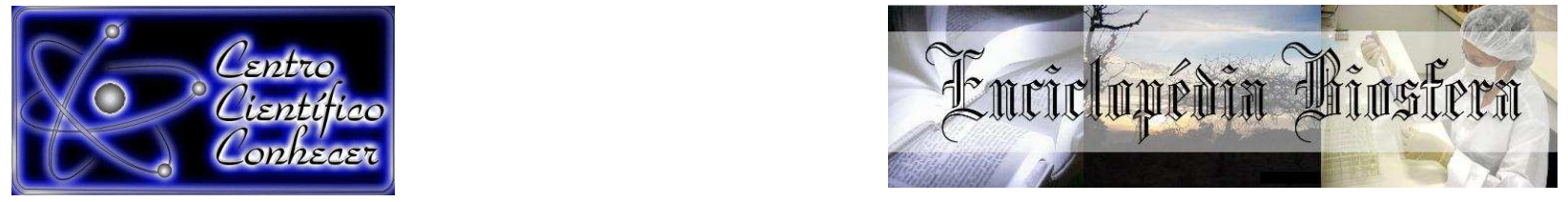

\title{
POTENCIAL FISIOLÓGICO DE DIÁSPOROS DE Punica granatum L. APÓS FERMENTAÇÃO EM ÁCIDO GIBERÉLICO
}

\author{
Monalisa Alves Diniz da Silva Camargo Pinto ${ }^{1}$, Ariana Veras de Araújo², Vanessa \\ Renata de Sousa Barbosa ${ }^{3}$, Alexandre Camargo Pinto ${ }^{4}$
}

1. Professora Doutora Adjunta IV da UFRPE/UAST. monallyysa@yahoo.com.br

2. Mestre em Produção Vegetal pela Universidade Federal Rural de Pernambuco /Unidade Acadêmica de Serra Talhada (UFRPE/UAST) e Doutoranda em Agronomia/Fitotecnia pela Universidade Federal do Ceará (UFC).

3. Mestre em Produção Vegetal pela UFRPE/UAST.

4. Engenheiro Agrônomo.

Universidade Federal Rural de Pernambuco/Unidade Acadêmica de Serra Talhada (UFRPE/UAST), Caixa Postal 063, CEP 56900-000, Serra Talhada, PE, Brasil.

Recebido em: 03/10/2016 - Aprovado em: 21/11/2016 - Publicado em: 05/12/2016 DOI: 10.18677/EnciBio_2016B 077

\begin{abstract}
RESUMO
A romã (Punica granatum L.) destaca-se por reunir propriedades antiinflamatórias e antioxidantes, principalmente nos frutos. Seus diásporos possuem como envoltório a sarcotesta, a qual proporciona uma reduzida germinação. A remoção da sarcotesta e o tratamento dos diásporos com giberelina poderiam favorecer a germinação. Objetivou-se avaliar o efeito de diferentes concentrações de ácido giberélico $\left(\mathrm{GA}_{3}\right)$ por dois períodos de fermentação na emergência de plântulas de romã. 0 experimento foi disposto em arranjo fatorial $5 \times 2+1$, com a imersão dos diásporos em zero; $100 ; 200 ; 500$ e $1000 \mathrm{mg} \mathrm{L}^{-1}$ de $\mathrm{GA}_{3}$, na forma do produto comercial Pro$\mathrm{Gibb}^{\circledR}$, por dois períodos de fermentação (48 e $72 \mathrm{~h}$ ), como controle utilizou-se diásporos secos (sem fermentação). A concentração zero constituiu na fermentação das sementes em água destilada. Avaliou-se porcentagem de plântulas normais emersas, tempo médio e índice de velocidade de formação das plântulas normais, altura e peso da matéria seca da parte aérea. Com o aumento das concentrações de $\mathrm{GA}_{3}$ houve redução tanto no número de plântulas emersas como no índice de velocidade de emergência; o peso da matéria seca também declinou, no entanto, não influenciou no tempo médio necessário para a formação das plântulas, independentemente do período de fermentação. A fermentação dos diásporos de romã em solução de $\mathrm{GA}_{3}$, por 48 e $72 \mathrm{~h}$, resultou na redução da emergência, mas as plântulas formadas não apresentaram alteração no vigor.
\end{abstract}

PALAVRAS-CHAVE: pré-tratamento, romã, vigor.

\section{PHYSIOLOGICAL POTENTIAL OF DIASPORES OF Punica granatum L. AFTER FERMENTATION IN ACID GIBBERELLIC}

\begin{abstract}
Pomegranate (Punica granatum L.) stands out by gathering anti-inflammatory and antioxidant properties, mainly in fruits. Their diaspores have to wrapping the sarcotesta, which provides a reduced germination. The removal of sarcotesta and treatment of the seeds with gibberellin could promote germination. This study aimed to evaluate the effect of different concentrations of gibberellic acid $\left(\mathrm{GA}_{3}\right)$ for two
\end{abstract}


periods of fermentation in emergence of seedlings of pomegranate. The experiment was disposed in a factorial arrangement $5 \times 2+1$, with the immersion of diaspores in zero; $100 ; 200 ; 500$ and $1000 \mathrm{mg} \mathrm{L}^{-1} \mathrm{GA}_{3}$, in the form of the commercial product Pro$\mathrm{Gibb}^{\circledR}$ by two fermentation periods (48 and $72 \mathrm{~h}$ ) was used as a control dried diaspores (without fermentation). The concentration is zero in the seed fermentation in distilled water. It was evaluated percentage of normal seedlings emersed, average time and speed index formation of normal seedlings, height and weight of the dry matter of the aerial part. With the increase in $\mathrm{GA}_{3}$ concentrations decreased in both the number of emerged seedlings as the emergency speed index; the dry weight also decreased, however, did not affect the average time required for the formation of seedling, regardless of the fermentation period. The fermentation of pomegranate diaspores in $\mathrm{GA}_{3}$ solution for 48 and $72 \mathrm{~h}$ resulted in the reduction of emergency, but the seedlings formed no change at the vigour.

KEYWORDS: pretreatment, pomegranate, vigour.

\section{INTRODUÇÃO}

A romã (Punica granatum L.) atualmente é bastante requisitada pelas indústrias farmacêutica e de cosmético, tendo sido comprovada a presença de punicalagina, um tanino hidrolisável, com propriedades anti-inflamatória e antioxidante (GONZÁLEZ-MOLINA et al., 2009), principalmente na casca e no mesocarpo do fruto (FISCHER et al., 2011).

Por causa da germinação desuniforme, a qual está associada com a presença do envoltório carnoso presente nos diásporos de romã, comumente chamado de sarcotesta; ocorre um desenvolvimento heterogêneo das mudas no viveiro, predispondo um maior tempo de exposição das mudas à fatores bióticos, onerando os custos do produtor.

A sarcotesta está relacionada com a reduzida germinação de diásporos de algumas espécies, como romã (LOPES et al., 2001), biribá (Rollinia mucosa (Jacq.) Baill) (CAMPOS et al., 2015), jaracatiá (Jaracatia spinosa (Aubl.) A. DC) (FREITAS et al., 2011); devido à presença de substâncias inibidoras como esteróides, triterpenóides e açúcares redutores, que funcionariam como uma barreira à entrada de água para o interior dos diásporos (MARTINS et al., 2010).

A adoção de métodos físicos, mecânicos ou químicos pode favorecer a degradação da sarcotesta. LOPES et al. (2001) recomendaram a fermentação em água destilada e açúcar para diásporos de romã por 72 h. Já BEZERRA et al. (2015) ao testarem diferentes métodos de extração (fricção em peneira, ácido sulfúrico, centrifugação e fermentação) de mucilagem em diásporos de genipapo (Genipa americana L.), constataram que tanto o uso da fricção em peneira como da fermentação proporcionaram uma emergência mais rápida e uma maior quantidade de plântulas normais, sendo que estas apresentaram um maior comprimento e peso da matéria seca.

Por sua vez, SILVA et al. (2015) concluíram que tanto a germinação como a formação das plântulas de maracujá apresentaram decréscimos quando adotou-se extração mecânica para remover o arilo. Apesar de a fermentação ser a principal metodologia adotada para extrair a mucilagem dos diásporos, isto não quer dizer que outros métodos não possam ser utilizados, desde é claro que não interfiram de modo negativo no vigor e na germinação dos diásporos. Em função de cada espécie possuir as suas características morfofisiológicas, é preciso pesquisar qual o melhor método de extração (OSIPI et al., 2011). 
Além da sarcotesta, o balanço hormonal também interfere na expressão do potencial germinativo, assim a submissão dos diásporos aos reguladores vegetais pode favorecer a manifestação do seu potencial fisiológico. SANTOS et al. (2013) constataram que a imersão dos diásporos de maracujazeiro amarelo (Passiflora edulis Sims f. flavicarpa Deg) em $\mathrm{GA}_{3}$ estimulou a germinação e reduziu o número de diásporos mortos.

A giberelina está diretamente relacionada com a síntese de enzimas digestivas, responsáveis pela degradação das substâncias de reserva em substâncias solúveis e difusíveis, as quais são transferidas para os pontos de crescimento no eixo embrionário, favorecendo a elongação celular e, consequentemente, culminando com a protrusão radicular (TAIZ \& ZEIGER, 2013).

Assim, objetivou-se avaliar o efeito de diferentes concentrações de $\mathrm{GA}_{3}$, na forma do produto comercial Pro-Gibb ${ }^{\circledR}$, por dois períodos de fermentação na emergência de plântulas de romã.

\section{MATERIAL E MÉTODOS}

Os frutos maduros de romã foram adquiridos no comércio de Serra TalhadaPernambuco e transportados para o Laboratório de Biologia da Universidade Federal Rural de Pernambuco/Unidade Acadêmica de Serra Talhada (UFRPE/UAST). A extração dos diásporos foi feita manualmente, sem danificá-los, de forma que a sarcotesta fosse preservada e selecionou-as quanto ao tamanho, forma e cor.

$\mathrm{O}$ experimento foi conduzido em delineamento inteiramente ao acaso com cinco repetições de 25 diásporos, em arranjo fatorial $5 \times 2+1$, onde os diásporos

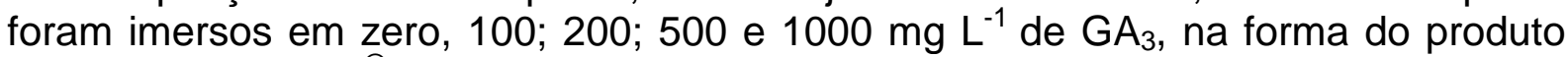
comercial Pro-Gibb ${ }^{\circledR}$, por dois períodos de fermentação (48 e 72 h), como controle utilizou-se diásporos secos (sem fermentação). A concentração zero constituiu na fermentação dos diásporos em água destilada.

Após a fermentação dos diásporos em água e nas concentrações de $\mathrm{GA}_{3}$, os mesmos foram semeados em fibra de coco. O experimento foi mantido em condições ambiente de umidade relativa média do ar de $52,3 \%$ e temperatura média de $25,9 \stackrel{\circ}{\circ}$. A irrigação do substrato foi diária por 30 dias.

Os tratamentos foram avaliados quanto as seguintes características: porcentagem de emergência (PE) das plântulas normais; índice de velocidade de emergência (IVE), registrando-se diariamente a quantidades de plântulas emersas desde a emergência até sua estabilização, segundo MAGUIRE (1962); e tempo médio de emergência (TME) calculado conforme LABOURIAU \& VALADARES (1976).

No $30^{\circ}$ dia a altura da parte aérea (APA) foi mensurada com régua milimetrada (cm plântula ${ }^{-1}$ ), posteriormente após 0 corte das plântulas na região do colo, acondicionou-se a parte aérea em sacos de papel $\mathrm{Kraft}^{\circledR}$, seguido de secagem à $65{ }^{\circ} \mathrm{C}$ durante $24 \mathrm{~h}$, depois deste período o material foi pesado em balança analítica (precisão de 0,001 g), segundo NAKAGAWA (1999), com os resultados expressos em g plântula ${ }^{-1}$, determinando-se o peso da matéria seca da parte aérea (PMSPA).

Além da análise de variância pelo teste $F$, empregou-se o teste de Dunnett (comparação da testemunha com os tratamentos) e de Tukey (comparação dos tratamentos), com $5 \%$ de probabilidade, utilizando-se o software ASSISTAT ${ }^{\circledR}$, versão 7.7 beta (SILVA \& AZEVEDO, 2009).

Para atender aos testes de normalidade e homogeneidade, os valores da variável tempo médio de emergência foram transformados através da fórmula $X=$ 
$1 / \sqrt{\mathrm{X}}$. A análise de regressão $(P \leq 0,05)$ foi empregada quando se verificou que as concentrações do $\mathrm{GA}_{3}$ apresentaram diferença estatística.

\section{RESULTADOS E DISCUSSÃO}

Ao analisar os tratamentos, em que os diásporos de romã foram submetidos, verificou-se que houve interação entre as concentrações do $\mathrm{GA}_{3}$ e os períodos de fermentação para o TME e o PMSPA (Tabela 1).

TABELA 1. Valores de F para a porcentagem de emergência (PE), índice de velocidade de emergência (IVE), tempo médio de emergência (TME), altura da parte aérea (APA) e peso da matéria seca da parte aérea (PMSPA) de plântulas de Punica granatum L. em função das concentrações (C) do ácido giberélico e dos períodos de fermentação (PF)

\begin{tabular}{lccccc}
\hline \multirow{2}{*}{ Fatores de Variação } & \multicolumn{5}{c}{ Valores de F } \\
\cline { 2 - 6 } & PE (\%) & IVE & $\begin{array}{c}\text { TME } \\
\text { (dias) }\end{array}$ & APA (cm) & $\begin{array}{c}\text { PMSPA } \\
(\mathrm{g})\end{array}$ \\
\hline Concentrações (C) & $5,81^{* *}$ & $5,46^{* *}$ & $0,38 \mathrm{~ns}$ & $2,27 \mathrm{~ns}$ & $6,35^{* *}$ \\
Períodos de Fermentação (PF) & $2,46 \mathrm{~ns}$ & $1,52 \mathrm{~ns}$ & $0,22 \mathrm{~ns}$ & $0,13 \mathrm{~ns}$ & $4,76^{*}$ \\
Interação C X PF & $1,66 \mathrm{~ns}$ & $1,75 \mathrm{~ns}$ & $0,10^{*}$ & $0,35 \mathrm{~ns}$ & $3,92^{* *}$ \\
Interação X Controle & $3,97 \mathrm{~ns}$ & $8,34^{* *}$ & $0,64 \mathrm{~ns}$ & $15,40^{* *}$ & $7,48^{* *}$ \\
\hline CV (\%) & 28,69 & 31,64 & 35,10 & 16,19 & 33,40 \\
\hline
\end{tabular}

Efeito significativo a $1 \%\left({ }^{* *}\right)$, a $5 \%\left({ }^{*}\right)$ e não significativo (ns), Coeficiente de variação (CV).

Quando a interação dos tratamentos foi comparada com as médias do tratamento controle, observou-se efeito significativo para os parâmetros IVE, APA e PMSPA. Já na avaliação dos fatores isoladamente, constatou-se efeito significativo quanto à concentração de $\mathrm{GA}_{3}$ para a PE, IVE e PMSPA (Tabela 1).

A PE e o TME de plântulas de romã cujos diásporos foram fermentados em água ou em $\mathrm{GA}_{3}$, independente da concentração, não diferiram do tratamento controle; contudo, o IVE diferiu significativamente do controle, quando os diásporos foram fermentados em água destilada e em $500 \mathrm{mg} \mathrm{L}^{-1}$ de $\mathrm{GA}_{3}$ por $72 \mathrm{~h}$ e na concentração de $100 \mathrm{mg} \mathrm{L}^{-1}$ pelos períodos de 48 e $72 \mathrm{~h}$ (Tabela 2).

TABELA 2. Porcentagem de emergência (PE), índice de velocidade de emergência (IVE), tempo médio de emergência (TME), altura da parte aérea (APA) e peso da matéria seca da parte aérea (PMSPA) de plântulas de Punica granatum L. em função da concentração do ácido giberélico e do período de fermentação

\begin{tabular}{lccccc}
\hline $\begin{array}{l}\text { Concentrações de ácido giberélico }(\mathrm{mg} \\
\mathrm{L}^{-1} \text { )/períodos de fermentação }(\mathrm{h})\end{array}$ & $\mathrm{PE}(\%)$ & $\mathrm{IVE}$ & $\begin{array}{c}\text { TME } \\
(\text { dias})\end{array}$ & $\begin{array}{c}\text { APA } \\
(\mathrm{cm})\end{array}$ & $\begin{array}{c}\text { PMSPA } \\
(\mathrm{g})\end{array}$ \\
\hline zero (água)/48 & 58,4 & 0,78 & 0,41 & 3,05 & 0,167 \\
zero (água)/72 & 67,2 & $0,92^{*}$ & 0,40 & 2,96 & $0,197^{*}$ \\
$100 / 48$ & 67,2 & $0,89^{*}$ & 0,40 & $3,40^{*}$ & 0,181 \\
$100 / 72$ & 63,2 & $0,89^{*}$ & 0,40 & 3,07 & $0,184^{*}$ \\
$200 / 48$ & 60,8 & 0,84 & 0,39 & 2,80 & $0,204^{*}$ \\
$200 / 72$ & 59,2 & 0,84 & 0,43 & 2,72 & 0,167 \\
$500 / 48$ & 64,8 & $0,91^{*}$ & 0,44 & $3,19^{*}$ & $0,202^{*}$ \\
$500 / 72$ & 40,0 & 0,53 & 0,44 & $3,29^{*}$ & 0,068 \\
$1000 / 48$ & 42,4 & 0,54 & 0,44 & $3,27^{*}$ & 0,103 \\
$1000 / 72$ & 29,6 & 0,40 & 0,50 & $3,42^{*}$ & 0,086 \\
Controle (Sem fermentação) & 40,8 & 0,44 & 0,37 & 2,21 & 0,091 \\
\hline "Médias diferem significativamente daquelas do controle (teste de Dunnett; $P<0,05)$.
\end{tabular}


Quanto à APA, diferenças foram verificadas entre as plântulas do controle e àquelas obtidas dos diásporos fermentados por $48 \mathrm{~h}$ nas concentrações de 100; 500 e $1000 \mathrm{mg} \mathrm{L}^{-1}$ e por $72 \mathrm{~h}$ nas concentrações de 500 e $1000 \mathrm{mg} \mathrm{L}^{-1}$ de $\mathrm{GA}_{3}$. Já os tratamentos que proporcionaram diferença significativa com relação ao tratamento controle quanto ao PMSPA foram os que consistiram na fermentação em água e em $100 \mathrm{mg} \mathrm{L}^{-1}$ de $\mathrm{GA}_{3}$ por $72 \mathrm{~h}$ e em 200 e $500 \mathrm{mg} \mathrm{L}^{-1}$ por $48 \mathrm{~h}$ (Tabela 2).

A análise do efeito das concentrações de $\mathrm{GA}_{3}$ sobre o potencial fisiológico dos diásporos de romã, evidenciou que com o aumento das concentrações houve redução tanto na PE como no IVE de plântulas, sugerindo que a fermentação em água $\left(0 \mathrm{mg} \mathrm{L}^{-1}\right)$ ou em $100 \mathrm{mg} \mathrm{L}^{-1}$ de $\mathrm{GA}_{3}$ já favorece uma emergência rápida $\mathrm{e}$ uniforme de plântulas de romã (Figura 1).

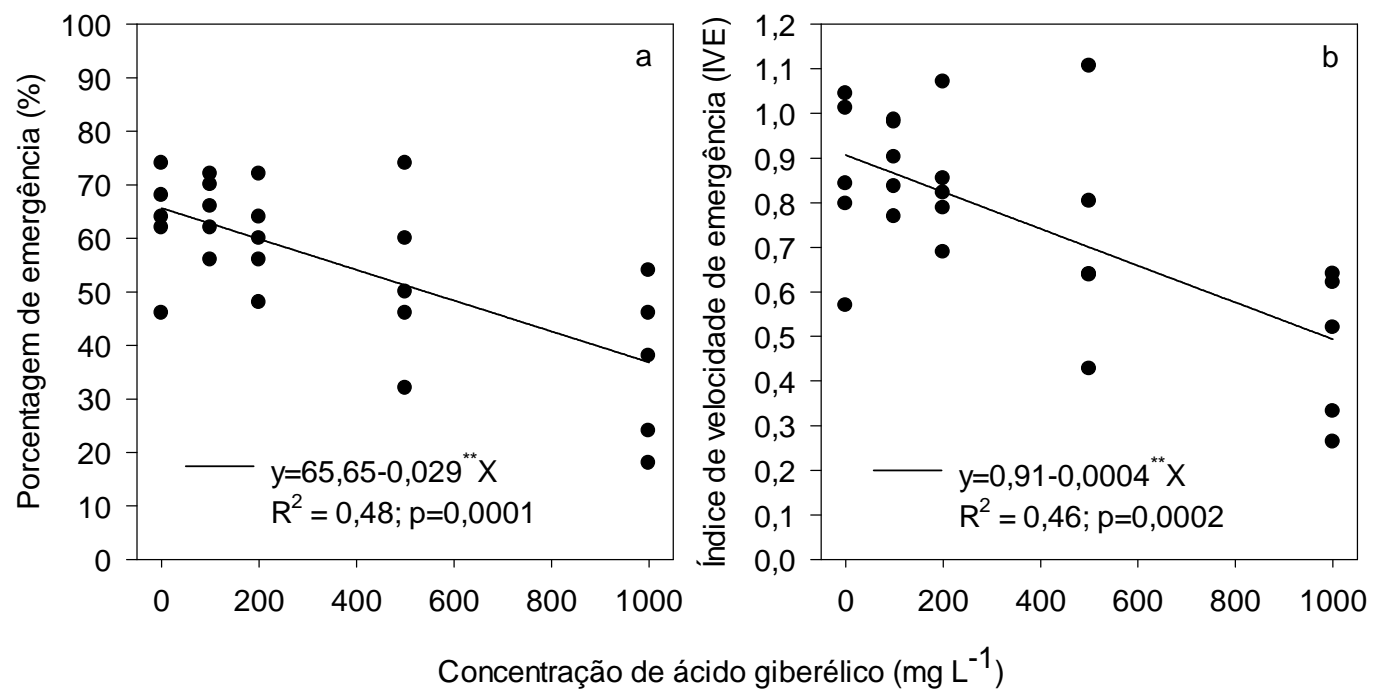

FIGURA 1. Porcentagem de emergência (a) e índice de velocidade de emergência (b) de plântulas provenientes de diásporos de Punica granatum $\mathrm{L}$. fermentados em diferentes concentrações de ácido giberélico.

A aplicação de $\mathrm{GA}_{3}\left(\right.$ Pro-Gibb $\left.^{\circledR}\right)$ nas concentrações de zero; 250; 500; 750 e $1000 \mathrm{~g} \mathrm{~L}^{-1}$ por $24 \mathrm{~h}$ não estimulou a PE e o IVE de plântulas de pitomba (Talisia esculenta (A. St.-Hil.) Radlk.) (VIEIRA \& GUSMÃO, 2006). Em contrapartida, a embebição de diásporos de jenipapo (G. americana L.) em giberelina $\left(4 \% \mathrm{GA}_{3}\right)$ nas dosagens de 50; 100 e $200 \mathrm{~mL} \mathrm{~L}^{-1}$ por $12 \mathrm{~h}$ melhorou o desempenho das sementes quanto ao IVE, porém, as mesmas dosagens não influenciaram na PE (PRADO NETO et al., 2007).

Em diásporos de caquizeiro das espécies Dyospyros kaki L. e D. lotus L., o uso de $\mathrm{GA}_{3}$ não interferiu positivamente na $\mathrm{PE}$, sendo que o aumento das concentrações $\left(100 ; 200\right.$ e $\left.300 \mathrm{mg} \mathrm{L}^{-1}\right)$ da solução de $\mathrm{GA}_{3}$ propiciou uma redução da PE de plântulas normais (PECHE et al., 2016).

Para o TME observou-se interação entre as concentrações de $\mathrm{GA}_{3}$ e os períodos de fermentação, no entanto, nenhuma diferença significativa foi observada quanto ao tempo que as demais plântulas de romã levaram para emergir em relação à primeira plântula emergida, independentemente do tratamento utilizado (Tabela 3). 
TABELA 3. Tempo médio de emergência/TME (dias) de plântulas de Punica granatum $\mathrm{L}$. em função das concentrações do ácido giberélico $\left(\mathrm{mg} \mathrm{L}^{-1}\right)$ e dos períodos de fermentação

\begin{tabular}{lcc}
\hline Concentrações $\left(\mathrm{mg} \mathrm{L}^{-1}\right)$ & \multicolumn{2}{c}{ Períodos de Fermentação } \\
\cline { 2 - 3 } & $48 \mathrm{~h}$ & $72 \mathrm{~h}$ \\
\hline zero & $0,41 \mathrm{Aa}$ & $0,40 \mathrm{Aa}$ \\
100 & $0,40 \mathrm{Aa}$ & $0,40 \mathrm{Aa}$ \\
200 & $0,39 \mathrm{Aa}$ & $0,43 \mathrm{Aa}$ \\
500 & $0,44 \mathrm{Aa}$ & $0,44 \mathrm{Aa}$ \\
1000 & $0,44 \mathrm{Aa}$ & $0,50 \mathrm{Aa}$ \\
\hline
\end{tabular}

Médias seguidas pela mesma letra, maiúsculas nas linhas e minúsculas nas colunas, não diferem estatisticamente entre si pelo teste de Tukey a $5 \%$ de probabilidade.

Ao estudar o efeito do uso do $\mathrm{GA}_{3}$ na emergência de plântulas de piquizeiro (Caryocar brasiliense Camb.), LEÃO et al. (2012) averiguaram que dentre as sementes das 16 plantas matrizes avaliadas, somente as sementes da matriz 6 apresentaram o menor TME de plântulas, independente do tratamento utilizado (imersão em água ou em $500 \mathrm{mg} \mathrm{L}^{-1}$ de $\mathrm{GA}_{3}$ por $48 \mathrm{~h}$ ).

A avaliação da APA (Tabela 4) evidenciou que não ocorreu interação entre as concentrações do $\mathrm{GA}_{3}$ e os períodos de fermentação, e que isoladamente os referidos fatores também não proporcionaram diferença significativa na APA das plântulas de romã, cujo comprimento médio ficou em torno de $3,1 \mathrm{~cm}$ plântula ${ }^{-1}$.

TABELA 4. Altura da parte aérea/APA (cm plântula ${ }^{-1}$ ) de plântulas de Punica granatum $\mathrm{L}$. em função das concentrações do ácido giberélico $\left(\mathrm{mg} \mathrm{L}^{-1}\right)$ e dos períodos de fermentação

\begin{tabular}{lc}
\hline Concentrações $\left(\mathrm{mg} \mathrm{L}^{-1}\right)$ & APA $(\mathrm{cm})$ \\
\hline Zero & $3,00 \mathrm{a}$ \\
100 & $3,24 \mathrm{a}$ \\
200 & $2,76 \mathrm{a}$ \\
500 & $3,24 \mathrm{a}$ \\
1000 & $3,34 \mathrm{a}$ \\
\hline Períodos de Fermentação & \\
\hline $48 \mathrm{~h}$ & $3,14 \mathrm{a}$ \\
$76 \mathrm{~h}$ & $3,09 \mathrm{a}$ \\
\hline
\end{tabular}

Médias seguidas pela mesma letra, na coluna, não diferem estatisticamente entre si pelo teste de Tukey a $5 \%$ de probabilidade.

Diferentemente dos resultados do presente estudo, CAMPOS et al. (2015) observaram que com o aumento das concentrações do $\mathrm{GA}_{3}$, houve um incremento linear não só da porcentagem de plântulas normais e do IVE, como das características relacionadas ao crescimento de plântulas de biribá ( $R$. mucosa).

SANTOS et al. (2013) também observaram efeitos benéficos no vigor de plântulas de maracujá amarelo ( $P$. edulis), principalmente na altura da parte aérea e total, quando utilizaram $\mathrm{GA}_{3}$ em concentrações entre 128,0 e $160,0 \mathrm{mg} \mathrm{L}^{-1}$. Segundo NAKAGAWA (1999) a diferença observada no comprimento é ocasionada pelas condições fornecidas a semente durante o seu desenvolvimento ou por ocasião do processo germinativo, sendo que sementes vigorosas originam plântulas com alto 
índice de crescimento, em função da máxima habilidade de transformação do suprimento de reservas dos tecidos de armazenamento e maior incorporação destes pelo eixo embrionário.

Com relação ao PMSPA (Figura 2), os tratamentos que proporcionaram os maiores acúmulos de fotoassimilados foram os que consistiram na fermentação em 200 e $500 \mathrm{mg} \mathrm{L}^{-1}$ de $\mathrm{GA}_{3}$ por $48 \mathrm{~h}$ e em água e $100 \mathrm{mg} \mathrm{L}^{-1}$ por $72 \mathrm{~h}$. Salienta-se que as concentrações de $1000 \mathrm{mg} \mathrm{L}^{-1}$ por 48 e $72 \mathrm{~h}$ e a de $500 \mathrm{mg} \mathrm{L}^{-1}$ por $72 \mathrm{~h}$ originaram as plântulas com os menores conteúdos de acúmulo de matéria seca.

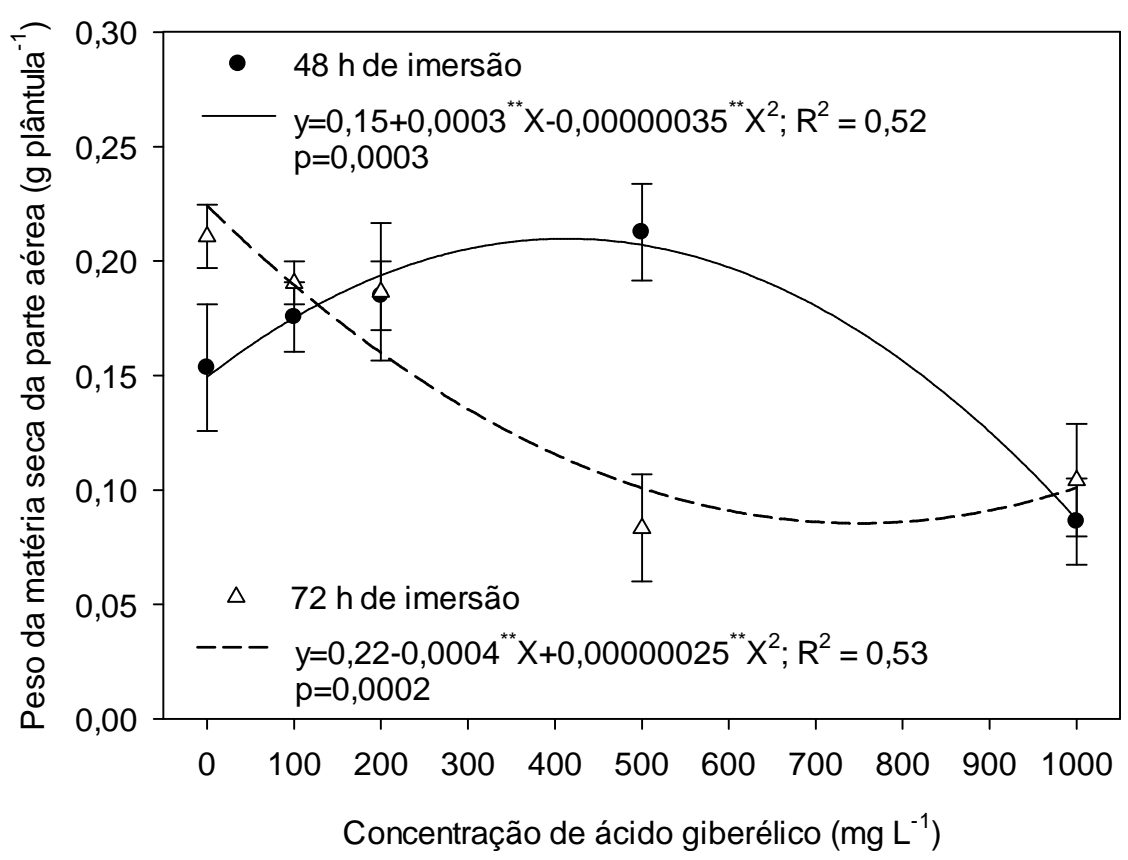

FIGURA 2. Peso da matéria seca da parte aérea de plântulas oriundas de diásporos de Punica granatum L. em função das concentrações do ácido giberélico e dos períodos de fermentação.

Da mesma forma que o tratamento controle, as concentrações de zero; 50 e $100 \mu \mathrm{L} \mathrm{L} \mathrm{L}^{-1}$ de giberelina líquida, não proporcionaram diferença significativa quanto ao acúmulo de matéria seca de plântulas de mamoneira (Ricinus comunis L.), no entanto, houve uma redução no peso da matéria seca quando os diásporos foram pré-embebidos na concentração de $150 \mu \mathrm{L} \mathrm{L}^{-1}$ (PEIXOTO et al., 2011).

Em diásporos de jambolão (Eugenia jambolana Lam.) a remoção da sua polpa por friç̧ão com areia, degustação humana e fermentação por 96 horas, resultou no maior conteúdo de matéria seca (ARAÚJO et al., 2015), o que poderia estar relacionado a uma maior retirada da polpa por tais procedimentos, e consequentemente eliminação de um possível inibidor da germinação.

\section{CONCLUSÃO}

De modo geral, o uso de $\mathrm{GA}_{3}$ pelos períodos de fermentação de 48 e $72 \mathrm{~h}$ propiciou um declínio na emergência, mas não influenciou no vigor das plântulas de romã. 


\section{AGRADECIMENTO}

À Universidade Federal Rural de Pernambuco/Unidade Acadêmica de Serra Talhada (UFRPE/UAST), Programa de Pós-Graduação em Produção Vegetal.

\section{REFERÊNCIAS}

ARAÚJO, L. R.; ALVES, E. U.; RODRIGUES, C. M.; RODRIGUES, A. A. M. Emergência e crescimento inicial de plântulas de Eugenia jambolana Lam. após remoção da polpa. Ciência Rural, v. 45, n. 1, p. 14-18, 2015. Disponível em: <http://www.scielo.br/pdf/cr/v45n1/0103-8478-cr-45-01-00014.pdf>. http://dx.doi.org/10.1590/0103-8478cr20120625.

BEZERRA, A. K. D.; SILVA, G. Z.; NASCIMENTO, L. C.; BRUNO, R. L. A.; MEDEIRO, J. G. Extração da mucilagem em sementes de Genipa americana L. visando o potencial fisiológico. Revista Ciência Agronômica, v. 46, n. 4, p. 786791, 2015. Disponível em: < http://www.ccarevista.ufc.br/seer/index.php/ccarevista/article/view/3765/1239>. DOI: 10.5935/1806-6690.20150066.

CAMPOS, L. F. C.; ABREU, C. M.; GUIMARÃES, R. N.; SElEGUINI, A. Escarificação e ácido giberélico na emergência e crescimento de plântulas de biriba. Ciência Rural, v. 45, n. 10, p. 1748-1754, 2015. Disponível em: <http://www.scielo.br/scielo.php?script=sci_arttext\&pid=S010384782015001001748> . DOI: http://dx.doi.org/10.1590/0103-8478cr20140249.

FISCHER, U. A.; CARLE, R.; KAMMERER, D. R. Identification and quantification of phenolic compounds from pomegranate (Punica granatum L.) peel, mesocarp, aril and differently produced juices by HPLC-DAD-ESI/MS ${ }^{n}$. Food Chemistry, v. 127, n. 2, p. 807-821, 2011. Disponível em: < http://www.sciencedirect.com/science/article/pii/S0308814611000707>. DOI: http://dx.doi.org/10.1016/j.foodchem.2010.12.156.

FREITAS, S. J.; BARROSO, D. G.; SILVA, R. F.; MARTINS, V. H. C. R.; FREITAS, M. D. S.; FERREIRA, P. R. Métodos de remoção da sarcotesta na germinação de sementes de jaracatiá. Revista Árvore, v. 35, n.1, p. 91-96, 2011. Disponível em: < http://www.scielo.br/scielo.php?script=sci_arttext\&pid=S0100-67622011000100011 >. DOI: http://dx.doi.org/10.1590/S0100-67622011000100011.

GONZÁLEZ-MOLINA, E.; MORENO, D. A.; GARCÍA-VIGUERA, C. A new drink rich in bioactives combining lemon and pomegranate juices. Food Chemistry, v. 115, n. 4, p. 1364-1372, 2009. Disponível em: <http://www.sciencedirect.com/science/article/pii/S0308814609000983>. DOI: http://dx.doi.org/10.1016/j.foodchem.2009.01.056.

LABOURIAU, L. G.; VALADARES, M. E. B. On the germination of seeds Calotropis procera (Ait.) Ait. f. Anais da Academia Brasileira de Ciências, v. 48, n. 2, p. 263284, 1976. 
LEÃO, E. F.; PEIXOTO, N.; MORAIS JÚNIOR, O. P. Emergência de plântulas de pequizeiro em função da planta matriz e uso de ácido giberélico. Pesquisa Agropecuária Tropical, v. 42, n. 4, p. 416-423, 2012. Disponível em: $<$ https://www.revistas.ufg.br/pat/article/view/18114/12629>.

LOPES, K. L.; BRUNO, R. L. A.; BRUNO, G. B.; AZEREDO, G. A. Comportamento de sementes de romã (Punica granatum L.) submetidas à fermentação e secagem. Revista Brasileira de Fruticultura, v. 23, n. 2, p. 369-372, 2001. Disponível em: <http://www.scielo.br/pdf/rbf/v23n2/7984.pdf>. DOI: http://10.1590/S010029452001000200034.

MAGUIRE, J. D. Speed of germination-aid in and evaluation for seedling emergence and vigour. Crop Science, Madison, v. 2, n. 1, p. 176-177, 1962.

MARTINS, C. M.; VASCONCELLOS, M. A. S.; ROSSETTO, C. A. V.; CARVALHO, M. G. Prospecção fitoquímica do arilo de sementes de maracujá amarelo e influência em germinação de sementes. Ciência Rural, v. 40, n. 9, p. 1934-1940, 2010. Disponível em: <http://www.scielo.br/pdf/cr/v40n9/a720cr2740.pdf>. DOI: http://dx.doi.org/10.1590/S0103-84782010000900013.

NAKAGAWA, J. Teste de vigor baseados no desempenho das plântulas. In: KRZYZANOWSKI, F. C.; VIEIRA, R. D.; FRANÇA NETO, J. B. (Eds). Vigor de sementes: conceitos e teses. Associação Brasileira de Tecnologia de Sementes, Comitê de Vigor de Sementes. Londrina: ABRATES, 1999.

OSIPI, E. A. F.; LIMA, C. B.; COSSA, C. A. Influência de métodos de remoção do arilo na qualidade fisiológica de sementes de Passiflora alata Curtis. Revista Brasileira de Fruticultura, Volume Especial, p. 680-685, 2011. Disponível em: < http://www.scielo.br/pdf/rbf/v33nspe1/a95v33nspe1.pdf>.

PECHE, P. M.; BARBOSA, C. M. A.; PIO, R.; SOUSA, P. H. A.; VALLE, M. H. Estratificação das sementes, ácido giberélico e temperatura na obtenção de portaenxertos de caquizeiros. Revista Ciência Agronômica, v. 47, n. 2, p. 387-392, $2016 . \quad$ Disponível em: < http://www.ccarevista.ufc.br/seer/index.php/ccarevista/article/view/3987/1373> DOI: 10.5935/1806-6690.20160046.

PEIXOTO, C. P.; SALES, F. J. S.; VIEIRA, E. L.; PASSOS, A. R.; SANTOS, J. M. S. Ação da giberelina em sementes pré-embebidas de mamoeira. Comunicata Scientiae, v. 2, n. 2, p. 70-75, 2011. Disponível em: < https://comunicatascientiae.com.br/comunicata/article/download/31/74>.

PRADO NETO, M.; DANTAS, A. C. V. L.; VEIRA, E. L.; ALMEIDA, V. O. Germinação de sementes de jenipapeiro submetidas à pré-embebição em regulador $e$ estimulante vegetal. Ciência e Agrotecnologia, v. 31, n. 3, p. 693-698, 2007. Disponível em: < http://www.scielo.br/pdf/cagro/v31n3/a14v31n3>.

SANTOS, C. A. C.; VIEIRA, E. L.; PEIXOTO, C. P.; LEDO, A. C. S. Germinação de sementes e vigor de plântulas de maracujazeiro amarelo submetidos à ação do 
ácido giberélico. Bioscience Journal, v. 29, n. 2, p. 400-407, 2013. Disponível em: <http://www.seer.ufu.br/index.php/biosciencejournal/article/view/14137>.

SILVA, F. A. S. E.; AZEVEDO, C. A. V. Principal Components Analysis in the Software Assistat-Statistical Attendance. In: WORLD CONGRESS ON COMPUTERS IN AGRICULTURE, 7. Reno-NV-USA: American Society of Agricultural and Biological Engineers, 2009.

SILVA, S. M.; OLIVEIRA, R. C.; ALMEIDA, R. F.; SÁ JÚNIOR, A.; SANTOS, C. M. Aryl removal methods and passion fruit seed positions: Germination and emergence. Journal of Seed Science, v. 37, n. 2, p. 125-130, 2015. Disponível em: <http://www.scielo.br/scielo.php?script=sci_arttext\&pid=S2317-

15372015000200125>. DOI: http://dx.doi.org/10.1590/2317-1545v37n2146373.

TAIZ, L.; ZIEGER, E. Fisiologia Vegetal, 5 ed. Porto Alegre: Artmed, 2013. 918p.

VIEIRA, F. A.; GUSMÃO, E. Uso de giberelinas na emergência de plântulas de Talisia esculenta (A. St.-Hil.) Radlk. Revista Científica Eletrônica de Engenharia Florestal, v. 8, n. 8, p. 1-10, 2006. Disponível em: $<$ http://faef.revista.inf.br/imagens_arquivos/arquivos_destaque/rgHejpnfP2jKAi0_201 3-4-26-10-46-57.pdf>. 